\title{
Atmospheric Chemistry Experiment (ACE) Measurements of Tropospheric and Stratospheric Chemistry and Long-Term Trends
}

\author{
Curtis P. Rinsland, NASA Langley Research Center, Atmospheric Sciences Competency, Mail Stop 401A, Hampton, \\ Virginia, U.S.A, (c.p.rinsland@larc.nasa.gov) \\ Peter Bernath, Department of Chemistry, University of Waterloo, Waterloo, Ontario, Canada (bernath@uwaterloo.ca) \\ Chris Boone, Department of Chemistry, University of Waterloo, Waterloo, Ontario, Canada (cboone@acebox.uwaterloo.ca) \\ Ray Nassar, Department of Earth and Planetary Sciences and Division of Engineering and Applied Sciences, Cambridge, MA U.S.A. \\ (ray@io.as.harvard.edu)
}

\begin{abstract}
We highlight chemistry and trend measurement results from the Atmospheric Chemistry Experiment (ACE) which is providing precise middle troposphere to the lower thermosphere measurements with a $0.02 \mathrm{~cm}^{-1}$ resolution Fourier transform spectrometer covering $750-4400 \mathrm{~cm}^{-1}$.
\end{abstract}

\section{Introduction}

The Atmospheric Chemistry Experiment (ACE) also known as SCISAT 1 is a Canadian lead solar occultation mission launched into a $74^{\circ}$ inclined orbit at $650 \mathrm{~km}$ altitude on August 12, 2003 [1]. The primary instrument is a $0.02 \mathrm{~cm}^{-1}$ resolution Fourier transform spectrometer covering $750-4400 \mathrm{~cm}^{-1}$ at 0.02 $\mathrm{cm}^{-1}$ resolution. There is also a UV-visible spectrometer measuring 285-1030 $\mathrm{nm}$ (MAESTRO), and imagers with filters at 0.525 and $1.02 \mu \mathrm{m}$. SCISAT-1 has yielded measurements from the middle troposphere to lower thermosphere and has resulted in detections of several new molecules, analysis of pollution in the tropics and the Arctic due to wildfires, measurements of trends and budgets of stratospheric chlorine and fluorine in addition to measurements of polar stratospheric and mesospheric clouds.

\section{Impact of Intense Solar Flares on Stratospheric $\mathrm{NO}_{\mathrm{x}}$}

The Sun produced some of the most powerful solar flares ever recorded between 18 October and 5 November 2003. ACE measurements of Arctic $\mathrm{NO}_{x}\left(\mathrm{NO}+\mathrm{NO}_{2}\right)$ vs. pressure from $0.07-2 \mathrm{hPa}(\sim 40-60 \mathrm{~km})$ during February and March 2004 showed the dilution of $\mathrm{NO}_{\mathrm{x}}$ resulting from photochemical loss in the sunlit atmosphere, and the time series of measurements were used to estimate the descent rate from the upper stratospheric $\mathrm{NO}_{\mathrm{x}}\left(\mathrm{NO}+\mathrm{NO}_{2}\right)$ time series [2].

\section{Stratospheric Trends and Budgets of Chlorine and Fluorine}

The capability to infer nearly all components of the stratospheric inventories of chlorine and fluorine from high spectral resolution solar occultation measurements was pioneered by the Atmospheric Trace Molecules Spectroscopy (ATMOS) Fourier transform spectrometer. The ACE instrument improves on the ATMOS design, and has been used to infer trends of both chlorine and fluorine species at a critical time when stratospheric chlorine is near its maximum. Trend studies from ATMOS and ACE measurement comparisons have been reported [3,4], in addition to the detections of HCFC-142b and CFC-113 [5]. Inventories for chlorine and fluorine in 2004 have been inferred [6,7], and the detection of COClF, a missing component in the chlorine and fluorine chemical families as been achieved from analysis of coadded ACE spectra [8]. The analysis is based on ATMOS-derived parameters from room-temperature laboratory spectra of the region containing its strongest infrared band [9]. Model-measurement distributions are roughly consistent [8], but the accuracy is limited by the large spectroscopic uncertainties and the weakness of the COClF absorption in the ACE spectra.

\section{Tropospheric Chemistry}

As shown previously by solar occultation sounders, frequent clear sky scenes occur in the middle and upper troposphere. ACE measures southern hemisphere lower to mid-latitudes during August to October when 
intense fires occur in tropical regions of Africa and South America (e.g., Fishman et al., [10]). Convection from those fires results in transport of the pollutant emissions from the surface to the middle and upper troposphere, where molecules with a sufficiently long lifetime can be measured by ACE. An example of time series of measurements by ACE during 2004 is shown in the correlated variations of the $\mathrm{CO}, \mathrm{C}_{2} \mathrm{H}_{6}$, and $\mathrm{HCN}$ upper tropospheric mixing ratio distributions [11]. Similar variations with time of the long-lived tracers $\mathrm{CO}, \mathrm{C}_{2} \mathrm{H}_{6}$, and $\mathrm{HCN}$, which were observed and traced to tropical fire regions by analysis with kinematic back trajectories.

ACE has detected several molecular species in the upper troposphere not previously observed from space. Methanol $\left(\mathrm{CH}_{3} \mathrm{OH}\right)$ [12] is the most abundant organic molecule in the troposphere and formic acid $(\mathrm{HCOOH})$, which is also ubiquitous in the troposphere with several identified sources. Measurements of $\mathrm{HCOOH}$ have been obtained with a variety of techniques with lifetimes ranging from several hours in the boundary layer to a few weeks in the upper troposphere [13]. Both are important oxygenated volatile organic compounds (OVOCs) with major limitations recognized in the ability of models to reproduce OVOC chemistry, particularly in the dry upper troposphere where OVOCs are a major source of $\mathrm{HO}_{\mathrm{x}}$ $\left(\mathrm{OH}+\mathrm{HO}_{2}\right)$ in the background troposphere. ACE $2004 \mathrm{CH}_{3} \mathrm{OH}$ measurements showed mixing ratios in aged fire plumes above 4000 pptv ( 1 pptv $=10^{-12}$ per unit volume) during 2004 and $\mathrm{HCOOH}$ in upper tropspheric mixing ratios up to $3.13 \mathrm{ppbv}\left(10^{-9}\right.$ per unit volume) in plumes during 2004 and 2005 [13].

ACE has also measured boreal regions where air quality is frequently impacted during summer by biomass burning. Summer 2004 ACE measurements show elevated upper tropospheric $\mathrm{CO}, \mathrm{C}_{2} \mathrm{H}_{6}, \mathrm{HCN}, \mathrm{CH}_{3} \mathrm{Cl}$, $\mathrm{CH}_{4}, \mathrm{C}_{2} \mathrm{H}_{2}, \mathrm{CH}_{3} \mathrm{OH}, \mathrm{HCOOH}$, and OCS mixing ratios with plumes up to $189 \mathrm{ppbv}$ ( $10^{-9}$ per unit volume) for $\mathrm{CO}, 1.40 \mathrm{ppbv}$ for $\mathrm{C}_{2} \mathrm{H}_{6}, 830 \mathrm{pptv}$ for $\mathrm{HCN}, 1.78 \mathrm{ppbv}$ for $\mathrm{CH}_{3} \mathrm{Cl}, 2.16 \mathrm{ppmv}$ (10 ${ }^{-6}$ per unit volume) for $\mathrm{CH}_{4}, 0.118 \mathrm{ppbv}$ for $\mathrm{C}_{2} \mathrm{H}_{2}, 3.89$ ppbv for $\mathrm{CH}_{3} \mathrm{OH}, 0.843$ ppbv for $\mathrm{HCOOH}$, and 0.543 ppbv for OCS in western Canada and Alaska at $50^{\circ} \mathrm{N}-68^{\circ} \mathrm{N}$ latitude between 29 June and 23 July 2004 [14].

\section{Polar Stratospheric Clouds}

ACE spectra show spectral features of polar stratospheric clouds during winter over in the Antarctic and the Arctic similar to the thermal emission measurements by MIPAS [15], but also with simultaneous observations of the spectral features at shorter wavelengths with the FTS, the two imagers, and MAESTRO. The MIPAS analyses yielded the identification of spectral features of small beta NAT particles in both the Arctic and Antarctic lower stratosphere. The same features are seen in the ACE spectra as illustrated in Figure 1. ACE measurements and fits taking into account molecular interfering molecules also show evidence for small beta NAT particles near $3330 \mathrm{~cm}^{-1}$ with differences in the locations of the peaks in current sets of imaginary indices of refraction.
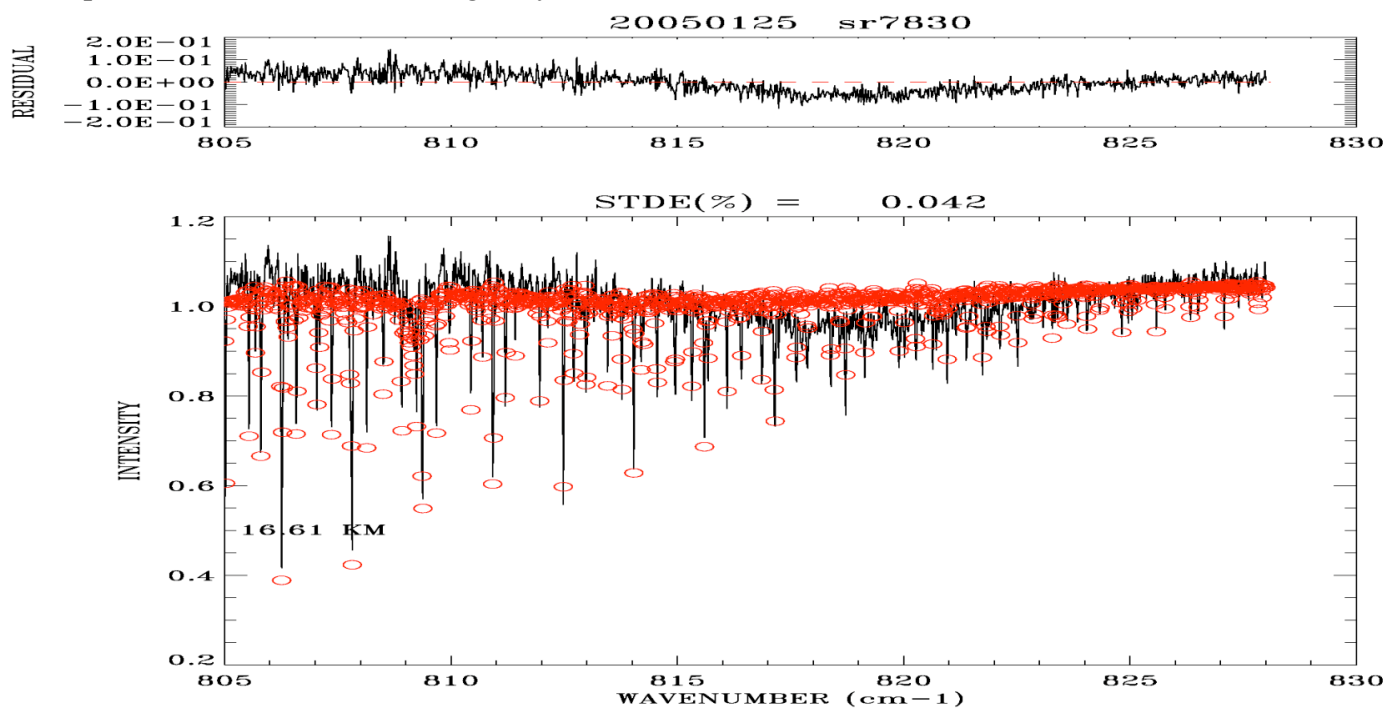

Figure 1. Measured and best-fit to an ACE Antarctic spectrum. Residuals showi the spectral signature of small beta NAT particles with peak absorption near $818 \mathrm{~cm}^{-1}$. 


\section{References}

[1] Bernath, P.F. et al., Atmospheric Chemistry Experiment (ACE): Mission overview, Geophys. Res. Lett., 32, L15S01, doi: 10.1029/2005GL022386, 2005.

[2] Rinsland, C.P. et al., Atmospheric chemistry experiment (ACE) Arctic stratospheric measurements of $\mathrm{NO}_{\mathrm{x}}$ during February and March 2004 : Impact of intense solar flares, Geophys. Res. Lett., 32, L16S05, doi: 10.1029/2005GL022425, 2005.

[3] Rinsland, C., et al. Trends of $\mathrm{HF}, \mathrm{HCl}, \mathrm{CCl}_{2} \mathrm{~F}_{2}, \mathrm{CCl}_{3} \mathrm{~F}, \mathrm{CHClF}_{2}(\mathrm{HCFC}-22)$ and $\mathrm{SF}_{6}$ in the lower stratosphere from Atmospheric Chemistry Experiment (ACE) and Atmospheric Trace Molecule Spectroscopy (ATMOS) measurement near $30^{\circ} \mathrm{N}$ latitude, Geophys. Res. Lett., 32, L16S03, doi: 10.1029/2005GL022415, 2005b.

[4] Rinsland, C.P. et al., Long-term stratospheric carbon tetrafluoride $\left(\mathrm{CF}_{4}\right)$ increase from 1985-2004 infrared solar occultation measurements, Geophys. Res. Lett.2 33, L02808, doi:10.1029/2005GL024709. 2006a.

[5] Dufour, P.F. et al., First measurements of CFC-113 and HFC142b from space using ACE-FTS infrared spectra, Geophys. Res. Lett., 32, L15S09, doi: 10.1029/2005GL022422, 2005.

[6] Nassar, R. et al. The global inventory of stratospheric chlorine in 2004, J. Geophys.Res., in press, 2006.

[7] Nassar, R., et al. A global inventory of stratospheric fluorine in 2004 based on ACE-FTS measurements, J. Geophys. Res.2in press, 2006.

[8] Rinsland, C.P. et al. Spectroscopic detection of COClF in the tropical and mid-latitude lower stratosphere from Atmospheric Chemistry Experiment infrared solar spectra: Preliminary retrievals and comparison with previous measurements and model calculations, J. Quant. Spectrosc. Radiat. Transfer, submitted, 2006.

[9] Brown, L.R. et al., Molecular line parameters for the Atmospheric Trace Molecule Experiment, Appl. Opt., 23, 5154-5182, 1987.

[10] Fishman, J. et al. Identification of widespread pollution in the southern hemisphere deduced from satellite analysis, Science, 252, 1693-1696, 1991.

[11] Rinsland, C. P., et al. Atmospheric Chemistry Experiment (ACE) measurements of elevated southern hemisphere upper tropospheric $\mathrm{CO}, \mathrm{C}_{2} \mathrm{H}_{6}, \mathrm{HCN}$, and $\mathrm{C}_{2} \mathrm{H}_{2}$ mixing ratios from biomass burning emissions and long-range transport, Geophys. Res. Lett., 32, L20803, doi: 10.1029/2005GL924214, 2005.

[12] Dufour, G.,, et al. First space-borne measurements of methanol inside aged tropical biomass burning plumes using the ACE-FTS instrument, Atmos. Chem. Phys.. Discuss, 6, 3945-3963, 2006.

[13] Rinsland, C. P., et al., First space-based measurements of formic acid ( $\mathrm{HCOOH})$ : Atmospheric chemistry experiment Austral spring 2004 and 2005 southern hemisphere tropical-mid-latitude upper tropospheric profile measurements, Geophys. Res. Lett.2 submitted, 2006.

[14] Rinsland, C.P. et al., Satellite boreal measurements over Alaska and Canada during June-July 2004: Simultaneous measurements of upper tropospheric $\mathrm{CO}, \mathrm{C}_{2} \mathrm{H}_{6}, \mathrm{HCN}, \mathrm{CH}_{3} \mathrm{Cl}, \mathrm{CH}_{4}, \mathrm{C}_{2} \mathrm{H}_{2}, \mathrm{CH}_{3} \mathrm{OH}, \mathrm{HCOOH}, \mathrm{OCS}$, and $\mathrm{SF}_{6}$, Global Biogeochem. Cycles, submitted, 2006.

[15] Höpfner, M. et al., MIPAS detects Antarctic belt of NAT PSCs caused by mountain waves, Atmos. Chem. Phys., 6, 1221-1230, 2006. 